\title{
WORK- RELATED MUSCULOSKELETAL SYMPTOMS AMONG NURSE STAFF IN ISMAILIA, EGYPT
}

\author{
By \\ Amer SA \\ Department of Community Medicine, Occupational Health Group, \\ Faculty of Medicine, Suez Canal University, Ismailia, Egypt.
}

\begin{abstract}
Introduction: Nursing career is considered one of the most physically laborious professions which are associated with high prevalence of work related musculoskeletal disorders (WMSDs). Although the latter is of major concern worldwide; limited epidemiological studies on WMSDs among nurses for referencing in Egypt. Aim of work:1) Assessing the prevalence of work related musculoskeletal symptoms (MSSs) among nurses in Suez Canal University Hospital and Ismailia General Hospital, 2) determining the associations between personal and occupational characteristics, physical risk factors with MSSs of back, neck, knee, wrist and shoulder and, 3) determining the relationship between presence of musculoskeletal symptoms and its sequel. Materials and methods: A cross sectional study is implemented on 135 female nurses with full history taking including medical and occupational histories. A modified form of Standardized Nordic Questionnaire (SNQ) and medical history checklist for symptoms of WMSDs from Canadian Center for Occupational Health and Safety is used for detection and assessment of musculoskeletal symptoms. Results: About 113(83.7\%) of the participants reported musculoskeletal symptoms: $91.4 \%$ in inpatient and ICU and $77.90 \%$ in outpatient. The most prevalent site was lower back $(79.3 \%, 58.4 \%)$ in inpatient, ICU and outpatients respectively, working in awkward positions and presence of work related symptoms with (OR:22.259, CI:4.58-108.10) $(\mathrm{p}<0.05)$, concentration for long periods $(\mathrm{OR}: 0.25, \mathrm{CI}: 0.07-0.95)(\mathrm{p}<0.05)$ presence of work shifts(OR:0.1.25, CI:1.14-1.38) $(\mathrm{p}<0.05)$ are the most perceived predictors for MSSs. Conclusion: A high frequency of Egyptian nurses reported WMSDs at some body sites; with the low back being the most injured site. Nurses in inpatients and ICU departments were more affected than outpatients. Working in awkward positions for long periods, presence of working shifts and concentration for long periods were the most perceived job risk factors.
\end{abstract}

Key words: Musculoskeletal symptoms, Nurse staff, Physical risk factors and Work shift. 


\section{Introduction}

Nursing career is considered one of the most physically laborious professions which is associated with high prevalence of work related musculoskeletal disorders (WMSDs) which are of major concern worldwide (Kee and Seob 2007 ; Nur et al.,2016). The incidence rate of WMSDs was 38 cases per every 10,000 workers; it is responsible for $34 \%$ of occupational illnesses (Nur et al., 2016). About $33 \%$ of the hospital staff is nurses which are accounting for $60 \%$ of the recorded occupational injuries (Wilkinson et al., 1992 and Tinubu et al., 2010). Bernal et al., 2015 describe MSDs as manifestations elicited or aggravated by long term exposure to certain hazards at the workplace including discomfort and pain in body structures, such as muscles, joints, bones, tendons, nerves and supporting blood vessels. Work-related MSDs have adverse outcomes on quality of life, productivity, increase work limitation, absenteeism, transfer to another work, and disabilities (Hagberg et al., 2012 and Taghinejad et al., 2016). Many risk factors which have been divided into intrinsic personal characteristics (such as age, tobacco smoking and body size variability) (Botha and Bridger 1998; Smith and Leggat 2003a; and Smith et al., 2003b), or extrinsic factors relating to occupational nature (such as strenuous work tasks, awkward posture, repetitive work, heavy lifting and manual handling tasks) (Yip 2001 and Smith et al. 2005). These work tasks are usually performed manually without assistance of equipment. So, nurses are significantly exposed to physical bodily health hazards and sooner or later to high risk of musculoskeletal injury (Nelson et al. 2003). The importance of psychosocial factors (such as limited work-support from superiors, poor job satisfaction and low mood) has also been demonstrated in recent years to have an important role in MSS (Bongers et al. 2002). Numerous literatures have identified the prevalence and risk factors of WMSDs among nurses, however, limited epidemiological studies were conducted on WMSDs among nurses for referencing in Egypt.

\section{Aim of work}

1) Assessing the prevalence of work related musculoskeletal symptoms 
(MSSs) among nurses in Suez Canal University Hospital and Ismailia General Hospital, 2) determining the associations between personal and occupational characteristics, physical risk factors with MSSs of back, neck, knee, wrist and shoulder and, 3) determining the relationship between presence of musculoskeletal symptoms and its sequel.

\section{Materials and methods}

- Study design: A cross sectional study was conducted to assess the prevalence and risk factors of work related musculoskeletal symptoms among nurses in Ismailia city, Egypt.

- Place and duration of the study: Two hospitals were selected; the first one was Hospital of Suez Canal University under direction of School of Medicine following Ministry of High Education, the second one was Ismailia General Hospital following Ismailia Health directorate which is the regional representative branch of Ministry of Health. The data was collected during the duration from April 2015 to January 2016.
-Study sample: The respondents are the nurse staff of inpatient and outpatient clinics in two previously mentioned hospitals. The total sample of 135 female nurses divided into 2 groups according to presence of work shift and nature of work tasks,

- The first group was $77(57.04 \%)$ nurses in the outpatient clinics where there were no work shifts and less job tasks required awkward positions (Nur et al., 2016).

- The second group was chosen from inpatient wards and ICU, 58 (42.96\%) participants, where work shifts exist and work tasks required awkward positions of the various body parts. Stratified random sample was used to select the participants from both hospitals under the study.

- Study methods:

Interview questionnaire was used:

The first part of the questionnaire required data on demographic characteristics including: age, gender, height, weight, education.

The second part was asking about occupational history including work 
duration, working hours, working days, shift work and specialty practice.

The third part contained questions about work tasks and job risk factors that may contribute to work related musculoskeletal symptoms (MSS).

The last forth part, that contains survey on musculoskeletal symptoms which is based on a modified form of Nordic Standardized Questionnaire (Kuorinka et al. 1987) and modification of medical history checklist: symptoms survey for WMSDs from Canadian Center for Occupational Health and Safety , 2013. MSS questions comprised anatomical illustrations which concentrated on the occurrence of symptoms (pain or discomfort) at definite 8 body sites taking place in the previous 12 months which consists of:3 upper limb parts (shoulder, elbow, wrist), 3 lower limb parts (hip, knees, ankle), and 2 trunk parts (neck, and lower back) occurring in the previous 12 months, these sites were shaded on the diagrams. In addition the questionnaire included questions regarding the sequel of symptoms of affection of daily life, persistence of pain and the need for medical treatment.

\section{Consent}

All nurses contributed in the study gave informed consents after appropriate clarification regarding confidentiality of data and aim and the objectives of the study.

\section{Ethical approval}

All procedures of the study were reviewed and approved by the ethical committee of Faculty of Medicine Suez Canal University and complied withlocal legislation and the Helsinki Declaration of Biomedical Ethics (World Medical Association Declaration, 2000).

\section{Data management}

The statistical analyses were carried out using SPSS software version 16.0 (SPSS Inc., Chicago, Illinois, USA). The $\alpha$ level was set at 0.05 , so the level of confidence was at $95 \%$. Data was stratified by hospital departments, differences between the departments evaluated using Pearson's chi square test and fisher exact test. The frequency distribution of impact of MSS upon daily work and activities, needed treatment, and persistence of pain according to different body sites was assessed. Logistic regression was implemented 
to determine probable risk factors for results stated as Odds Ratios (OR) with musculoskeletal symptoms as a whole $95 \%$ Confidence Intervals (95\% CI) for and for individual body sites. The Odds Ratios and Probability (p) values.

\section{Results}

A total of 135 nurses were interviewed, about 55 of the studied population was taken from Ismailia General Hospital, while 80 nurses were from Suez Canal University Hospital in Ismailia.

Table (1): characteristics of the studied sample.

\begin{tabular}{|l|l|c|c|}
\hline Variables & Category & No & \% \\
\hline Departments & Inpatient & 58 & 42.96 \\
\hline & Outpatient & 77 & 57.04 \\
\hline Smoking & & & \\
\hline & None & 135 & 100.00 \\
\hline No of diabetics & & & \\
\hline & & 19 & 14.07 \\
\hline Age ( years) & & & \\
\hline Work duration(years) & & Mean & SD \\
\hline Work hours/days & & 30.47 & 9.33 \\
\hline Work shift (days/month) & & 8.76 & 6.72 \\
\hline Weight (Kg) & & 5.65 & 1.23 \\
\hline Height(m) & & 6.84 & 4.54 \\
\hline BMI $\left(\right.$ Kg/m ${ }^{2)}$ & & 71.4 & 12.1 \\
\hline
\end{tabular}

BMI: Body mass Index

Table (1) showed that all the participants were non-smokers .Mean age, weight, height and body mass index of participants were $30.47 \pm 9.33$ years, $71.4 \pm 12.1 \mathrm{Kg}$, $1.61 \pm 0.08 \mathrm{~m}, 27.46 \pm 2.24 \mathrm{Kg} / \mathrm{m} 2$ respectively. Mean work duration, work hours / day and work shift were $8.76 \pm 6.72$ years, $5.65 \pm 1.23$ hours, and $6.84 \pm 4.54$ days/ month respectively. 
Table (2): Frequency distribution of musculoskeletal symptoms between inpatient and ICU and outpatient departments at different body sites.

\begin{tabular}{|c|c|c|c|c|c|c|c|c|}
\hline \multirow[b]{2}{*}{ Body Sites } & \multicolumn{2}{|c|}{$\begin{array}{c}\text { Inpatient } \\
\text { and } \\
\text { ICU(No=58) }\end{array}$} & \multicolumn{2}{|c|}{$\begin{array}{c}\text { Outpatient } \\
(\mathrm{No}=77)\end{array}$} & \multicolumn{2}{|c|}{$\begin{array}{l}\text { All nurses } \\
\left(\mathrm{No}_{0}=135\right)\end{array}$} & \multirow[t]{2}{*}{ OR(95\%CI) } & \multirow[t]{2}{*}{ p-value\# } \\
\hline & No & $\%$ & No & $\%$ & No & $\%$ & & \\
\hline Lower Back & 46 & 79.3 & 45 & 58.4 & 91 & 67.41 & $2.73(1.25-5.95)$ & $0.008 *$ \\
\hline Neck & 30 & 51.7 & 29 & 37.7 & 59 & 43.70 & $1.77(0.893 .54)$ & 0.073 \\
\hline Shoulder & 36 & 62.1 & 28 & 36.4 & 64 & 47.41 & $2.86(1.42-5.80)$ & $0.003^{*}$ \\
\hline Hand or wrist & 38 & 65.5 & 31 & 40.3 & 69 & 51.11 & $2.82(1.39-5.72)$ & $0.003^{*}$ \\
\hline Knee & 42 & 72.4 & 40 & 51.9 & 82 & 60.74 & $2.43(1.17-5.03)$ & $0.012^{*}$ \\
\hline Elbow & 5 & 8.6 & 2 & 2.60 & 7 & 5.19 & $0.28(0.05-1.51)$ & $0.131 \$$ \\
\hline Ankle & 5 & 8.6 & 4 & 5.2 & 9 & 6.67 & $0.58(0.15-2.27)$ & 0.430 \\
\hline Anybody site & 53 & 91.4 & 60 & 77.90 & 113 & 83.7 & $0.33(0.12-0.96)$ & $0.036^{*}$ \\
\hline
\end{tabular}

\$Fisher exact test,

\#chi square test

*statistically significant at $95 \%$ level of confidence

Table (2) elicited that $113(83.7 \%)$ of the participants reported 12 months prevalence rate of musculoskeletal symptoms, $91.4 \%$ in inpatient and ICU, 77.90\% in outpatient. The most prevalent site was lower back $(79.3 \%, 58.4 \%)$ in inpatient, ICU and outpatients respectively (OR 2.73, 95\%CI 1.25-5.95) $(\mathrm{p}<0.05)$ followed by knee $(72.4 \%, 51.9 \%)$ in inpatient, ICU and outpatient respectively(OR 2.43,CI $1.17-5.03)(\mathrm{p}<0.05)$, then hand or wrist $(65.5 \%, 40.3 \%)(\mathrm{OR} 2.82 \mathrm{CI} 1.39-5.72)$ and shoulder $(62.1 \%$,) in inpatient and ICU and neck $(37.7 \%)$ in outpatient, and the least frequent parts were ankle and elbow (8.6\% for both) in inpatient and ICU and $(5.2 \%, 2.60 \%)$ among outpatient nurse staff. 
Table (3): Impact of MSS upon daily work and activities, required treatment, and persistence of pain.

\begin{tabular}{|l|c|c|c|c|c|c|c|c|}
\hline & \multicolumn{2}{|c|}{$\begin{array}{c}\text { All nurses } \\
\text { (No=135) }\end{array}$} & \multicolumn{2}{c|}{$\begin{array}{c}\text { Affected daily } \\
\text { life }\end{array}$} & \multicolumn{2}{c|}{$\begin{array}{c}\text { Need } \\
\text { treatment }^{\text {b }}\end{array}$} & \multicolumn{2}{c|}{$\begin{array}{c}\text { Pain more } \\
\text { than week }\end{array}$} \\
\hline Body Site & No & \% & No & \% & No & \% & No & $\%$ \\
\hline Lower Back & 91 & 67.41 & 78 & 85.71 & 70 & 76.92 & 39 & 42.86 \\
\hline Neck & 59 & 43.70 & 47 & 79.66 & 31 & 52.54 & 34 & 57.63 \\
\hline Shoulder & 64 & 47.41 & 49 & 76.56 & 37 & 57.81 & 34 & 53.13 \\
\hline Hand & 69 & 51.11 & 45 & 65.22 & 37 & 53.62 & 35 & 50.72 \\
\hline Knee & 82 & 60.74 & 61 & 74.39 & 57 & 69.51 & 40 & 48.78 \\
\hline Elbow & 7 & 5.19 & 3 & 42.86 & 3 & 42.86 & 3 & 42.86 \\
\hline Ankle & 9 & 6.67 & 3 & 33.33 & 3 & 33.33 & 3 & 33.33 \\
\hline Anybody site & 113 & 83.70 & 94 & 69.6 & 91 & 67.4 & 48 & $35.6 \%$ \\
\hline
\end{tabular}

a. including work productivity or absenteeism, sports or home activities,

b. required professional medical treatment

Table (3) showed that the most frequent site which affect the daily life was the lower back (85.7\%) followed by neck (79.66), the least was ankle (33.33\%). According to the need for treatment, the most frequent site which needs treatment as a sequel of affection was the lower back (76.92\%), followed by knee $(69.51 \%)$, the least frequent was ankle (33.33\%). Regarding persistence of pain more than week, the most frequent body sites were neck and shoulder, which reported the following prevalence $(57.63 \%, 53.13 \%)$ respectively. The least frequent part was the ankle $(33.33 \%)$. 
Table (4): Logistic regression of factors affecting the presence of any MSS at any body site.

\begin{tabular}{|l|c|c|c|c|c|}
\hline \multirow{2}{*}{ Work tasks } & \multirow{2}{*}{ No } & \multirow{2}{*}{$\%$} & \multicolumn{2}{|c|}{ Logistic Regression } & \multirow{2}{*}{ p-value\# } \\
\cline { 4 - 6 } & & & OR & $(\mathbf{9 5 \%}$ CI $)$ & \\
\hline Fast continuous physical tasks & 71 & 52.59 & 3.626 & $(0.66-19.92)$ & 0.138 \\
\hline Pushing or lifting heavy weight & 65 & 48.19 & 1.989 & $(0.20-20.25)$ & 0.561 \\
\hline Work in awkward positions & 48 & 35.56 & 22.259 & $(4.58-108.10)$ & $0.000^{*}$ \\
\hline Lifting to the level of shoulder & 45 & 33.33 & 2.606 & $(0.47-14.58)$ & 0.276 \\
\hline Moving the waist & 43 & 31.85 & 3.059 & $(0.32-29.38)$ & 0.333 \\
\hline Repeated hand or wrist movement & 62 & 45.93 & 0.844 & $(0.05-13.38)$ & 0.904 \\
\hline Prolonged standing >4hours & 61 & 45.20 & 1.280 & $(.131-12.51)$ & 0.890 \\
\hline Double strenuous work & 68 & 50.37 & 0.369 & $(0.07-2.16)$ & 0.268 \\
\hline Concentration for long periods & 63 & 46.67 & 0.25 & $(0.07-0.95)$ & $0.042^{*}$ \\
\hline No enough time to finish tasks & 74 & 54.82 & 1.900 & $(0.25-14.25)$ & 0.532 \\
\hline Work tasks stopped before finishing & 81 & 60.00 & 0.356 & $(0.07-1.90)$ & 0.227 \\
\hline Shift work(present or absent) & 108 & 80 & 1.256 & $(1.14-1.38)$ & $0.004^{*}$ \\
\hline & Mean & SD & & & \\
\hline Duration of work & 25 & 8.76 & 1.049 & $(0.84-1.32)$ & 0.682 \\
\hline Working hours & 12 & 5.65 & 3.778 & $(0.88-16.21)$ & $0.044^{*}$ \\
\hline Constant & --- & --- & 0.004 & --- & 0.216 \\
\hline & & & & & \\
\hline
\end{tabular}

\#chi square test

* Statistically significant at $95 \%$ level of confidence.

In Table (4), the logistic regression analysis was applied to determine the predictors of the presence of work related musculoskeletal symptoms at anybody site, the factors entered the model as independent variables were expected as job physical stressors, in addition to duration of work, average working hours per day and presence of work shifts. The model reported that there were statistically significant association between working in awkward positions and presence of work related symptoms with (OR:22.259, CI:4.58-108.10) $(\mathrm{p}<0.05)$, concentration for long periods(OR:0.25, CI:0.07-0.95) $(\mathrm{p}<0.05)$ and presence of work shifts (OR:0.1.25, CI:1.14-1.38) $(\mathrm{p}<0.05)$. 
Table (5): Logistic regression of factors affecting the presence of any MSS at different body sites.

\begin{tabular}{|c|c|c|c|c|c|}
\hline \multirow{2}{*}{ Work tasks } & \multirow{2}{*}{ No } & \multirow{2}{*}{$\%$} & \multicolumn{2}{|c|}{ Logistic Regression } & \multirow{2}{*}{ p-value\# } \\
\hline & & & OR & $(95 \% \mathrm{CI})$ & \\
\hline \multicolumn{6}{|l|}{ Lower Back } \\
\hline No enough time to finish tasks & & & 4.140 & $(1.57-10.27)$ & $0.001 *$ \\
\hline Pushing or lifting heavy weights & & & 2.094 & $(0.89-4.09)$ & 0.09 \\
\hline Standing position $>4$ hours & & & 2.490 & $(1.02-6.07)$ & $0.04 *$ \\
\hline Shift Work & & & 1.116 & $(1.00-1.24)$ & $0.040 *$ \\
\hline \multicolumn{6}{|l|}{ Neck } \\
\hline Working hours & & & 0.271 & $(0.11-0.68)$ & $0.005 *$ \\
\hline Pushing or lifting heavy weight & & & 2.936 & $(1.06-8.11)$ & 0.038* \\
\hline Concentration for long periods & & & 3.034 & $(1.29-7.11)$ & $0.011 *$ \\
\hline $\begin{array}{l}\text { Work with neck flexed for long } \\
\text { periods(awkward position) }\end{array}$ & & & 3.370 & $(1.14-9.70)$ & $0.027 *$ \\
\hline Shift work & & & 3.080 & $(1.08-8.80)$ & $\mathbf{0 . 0 3} *$ \\
\hline \multicolumn{6}{|l|}{$\begin{array}{c}\text { Shoulder } \\
\end{array}$} \\
\hline $\begin{array}{l}\text { Work in extended body, lifting above } \\
\text { shoulder height (awkward position) }\end{array}$ & & & 16.131 & $(2.68-80.86)$ & $0.003 *$ \\
\hline Concentration for long periods & & & 2.042 & $(1.66-9.83)$ & $0.002 *$ \\
\hline $\begin{array}{l}\text { Work with waist twisted(awkward } \\
\text { position) }\end{array}$ & & & 8.402 & $(1.91-21.35)$ & $0.003 *$ \\
\hline Pushing or lifting heavy weights & & & 2.950 & $(0.87-9.97)$ & 0.08 \\
\hline \multicolumn{6}{|l|}{ Knee } \\
\hline Awkward position & & & 3.769 & $(1.47-9.16)$ & $0.005 *$ \\
\hline Manual handling of patient from/to bed & & & 3.101 & $(1.30-7.41)$ & 0.011* \\
\hline Standing position $>4$ hours. & & & 2.344 & $(0.97-5.65)$ & $0.021 *$ \\
\hline \multicolumn{6}{|l|}{\begin{tabular}{|c|} 
Hand \\
\end{tabular}} \\
\hline Manual handling of patient from/to bed & & & 3.977 & $(1.17-13.54)$ & $0.027 *$ \\
\hline Concentration for long periods & & & 5.210 & $(1.83-14.82)$ & $0.002 *$ \\
\hline Working hours & & & 0.689 & $(0.47-1.01)$ & 0.056 \\
\hline Shift work & & & 1.119 & $(0.98-1.27)$ & $0.046 *$ \\
\hline No enough time to finish tasks & & & 0.296 & $(0.12-0.75)$ & 0.010* \\
\hline Repeated hand and wrist movement & & & 5.570 & $(1.65-18.81)$ & $0.006 *$ \\
\hline Pressure finger or hand & & & 0.270 & $(0.08-0.96)$ & $0.045 *$ \\
\hline
\end{tabular}


Another logistic regression analysis was reported in Table (5) to determine the predictors of the presence of work related musculoskeletal symptoms at each individual body site. For everybody site the factors entered the model were specific physical job stress factors exerted by each site, in addition to duration of work, average working hours per day and presence of work shifts. For lower back; no enough time to finish tasks(OR:4.14, CI:1.57-10.27) $(\mathrm{p}<0.05)$, pushing or lifting heavy weights (OR:2.094, CI:0.89-4.09) $(\mathrm{p}<0.05)$, standing position $>4$ hours $(\mathrm{OR}: 2.49, \mathrm{CI}: 1.02-6.07)(\mathrm{p}<0.05) \quad$ and presence of work shifts (OR:1.116, CI:1.00-1.24) $(\mathrm{p}<0.05)$.

Regarding neck, pushing or lifting heavy weight concentration for long periods, working in awkward positions and shift work having Odds ratio nearly equal 3 or more than 3 with CI ranged between (1.06-9.70) and $(\mathrm{p}<0.05)$. Regarding shoulder, working in awkward positions including lifting above shoulder height (OR:16.13) and working with waist twisted (OR:8.40), concentration for long periods and pushing and lifting heavy weights with
Odds ratio more than 2 and $\mathrm{CI}$ ranged between (0.87-9.97) $(\mathrm{p}<0.05)$. Manual handling of patients from/to bed (OR: 3.10, CI: 1.30-7.41) $(\mathrm{p}<0.05)$, working in awkward position (OR: 3.77, CI: 1.47-9.61 $) \quad(\mathrm{p}<0.05)$ and standing position for more than 4 hours (OR: 0.40, CI: $0.18-0.87) \quad(\mathrm{p}<0.05)$ were significantly associated with increased risk for knee pains.

Concerning hand symptoms, repeated hand and wrist movements (OR:5.57, CI:1.65-18.81) ( $\mathrm{p}<0.05)$, concentration for long periods(OR:5.21, CI:1.83-14.82) $\quad(\mathrm{p}<0.05), \quad$ manual handling of patients from/to bed (OR:3.98, CI:1.17-13.54) $\quad(\mathrm{p}<0.05)$ and presence of work shifts (OR:1.12, CI:0.98-1.27) $(\mathrm{p}<0.05)$.

\section{Discussion}

Our work showed that there was a high prevalence of MSS among the studied nurse staff during the last 12 months preceding the interview $(83.7 \%)$ (Table 2). This is consistent with a study achieved in Sweden where the prevalence was $84 \%$ (Josephson et al., 1997) and in Japan was (85\%) (Smith et al., 2006). The current prevalence was higher than that which was recorded 
in china (70.0\%) (Smith et al. 2004), USA (72.5\%) (Trinkoff et al., 2002), Nigeria (78\%) (Tinubu et al., 2010), and in Uganda which was $(80.8 \%)$ (Munabi et al., 2014). In a systematic review on forty eight articles that assess the WRMSDs from 2003-2013 from different countries; the prevalence of all affected body sites was $71.85 \%$ (Ellapen and Narsigan, 2014). While lower percentage was reported by Smith et al., 2003b in Australia which was (92.6\%). Abo El Ata et al., 2016 reported high prevalence of WRMSDs (97.8\%) among operation room nurses in Cairo University Hospitals in Egypt. These differences can be accounted for demography and race differences. Also, variability in the assessment tools, structural differences in work locations, and differences in cultural perception (Yasobant and Rajkumar, 2014).

Our work showed that MSS are more common among inpatients and ICU departments than outpatients (Table 2), this may be due to those working in inpatients and ICU are more prone to extrinsic work risk factors like awkward positions, work shifts, manual handling of patients, more stressful working conditions, also, the nature of nurse staff in operation room showed more stressful physical working conditions (Abo El Ata et al. 2016).

In the current study, the most common affected site the lower back $(67.41 \%)$, followed by knee $(60.74 \%)$, then, hand $(51.11 \%)$, shoulder $(47.4 \%)$, neck $(43.7 \%)$ (Table 2). This in accordance with a study done in Cairo which reported that the lower back was the most affected site $(76.1 \%)$ (Abo El Ata et al. 2016), followed by knee $(67.9 \%)$. Another study done-in Zagazig, Egypt, by Sorour and Abd ElMaksoud, 2012; which elicits that the lower back was the commonest affected site $72.4 \%$, followed by neck $67.2 \%$, then shoulders $65.5 \%$.

In addition, the present research results are consistent with a study accomplished among nurses in India, which showed that the highest prevalent MSSs was the low back $48.2 \%$, followed by the shoulder $34.6 \%$, neck $33.1 \%$ and knees $29 \%$, the least prevalent site was elbow $1.88 \%$ and hip $1.6 \%$ (Anap et al. 2013). Another study done in Nigeria showed that the most affected body site was low-back (44.1\%), neck 
(28.0\%), and knees $(22.4 \%)$ (Tinubu et al., 2010). In a study done in Uganda by Munabi et al., 2014, declared that $61.9 \%$ of the participants stated that lower back was the most frequent site for musculoskeletal pain followed by neck (36.9\%). The systemic review achieved by Ellapen and Narsigan, 2014 reported that the most susceptible anatomical sites for musculoskeletal pain were the lower back, followed by neck and shoulders.

The results of the current investigation reported that $85.71 \%$, $76.92 \%$ of the respondents' back pain affect daily life such as work, sports or other activities and required medical treatment respectively (Table 3). In addition to $69.5 \%$ of those with knee pain sought medical treatment, while $57.3 \%$ of the respondents with neck pain and $53.13 \%$ of participants with shoulder pain reported persistence of pain more than one week duration (Table 3). This denoted that musculoskeletal symptoms are not always a transient incident; reasonably, they produced a prolonged disability that affects a nurse's working and daily life.
In a study conducted in Egypt by Abo El Ata et al. 2016, they detected that $22.3 \%$ and $17.4 \%$ of nurses were complaining of lower back pain and both shoulder and neck pains which lead to reduce high work performance. Another study conducted among Korean nurses, they found that $59.0 \%$ of nurses with low back pain were also associated with adverse effects on the nurses' daily activities. In the same study the highest proportion of MSS extended more than 1 week were recorded at the lower back $(49.0 \%)$ and shoulders $(40.7 \%)$. The authors interpreted these results that MSS at certain body sites is obviously associated with negative outcomes for Korean nurses.

The logistic regression has been applied to determine the risk factors for the musculoskeletal symptoms as a whole, work in awkward positions (like bending, outstretched hands and twisted waist, extended head) (OR:22.259, CI:4.58-108.10) $(\mathrm{p}<0.05)$, concentration for long periods(OR:0.25, CI:0.07-0.95) $\quad(\mathrm{p}<0.05)$, presence of work shifts(OR:1.26, CI:1.14-1.38) $(\mathrm{p}<0.05)$, and working hours per week (OR: 3.77, CI:0.88-16.21) (Table 4). 
Specifically for back, there was no enough time to finish tasks, presence of work shifts (OR: 1.17), pushing or lifting heavy weights (OR: 2.9) and standing position more than four hours (OR: $2.49,4.04)$ are predictors for back symptoms.

Working in awkward positions are associated in the current study with neck, shoulder, knee and hands pains. Awkward posture of nurses comprises frequently of forward extension of head and neck, lifting above shoulders height, twisted waist and flexion or twisting of the wrist. Sustained awkward position leads to muscle overload, exhaustion and fatigue which occurs as these uncomfortable body postures need more muscle work, so oxygenation of the muscle diminished in front of increased demands of muscle fibers leading to ischemia and pain (Hegazy et al., 2009). This was in agreement with an investigation achieved by Anap and colleagues which revealed that the prevalence of lower back, shoulder, neck and knee pain was due to working in a constant position for long time, flexion, extension, twisting and lifting, and taking care of large number of patients in a short time (Anap et al., 2013). The current results was in contrast with the results obtained by Daraiseh et al. 2010 who reported that low back pain was due to sustained awkward postures during work, unintended negligence of safe practices.

Long standing for more than four hours was reported in more than $45 \%$ of the current studied sample (Table 4), which oppose the ergonomic guidelines for standing that should not exceed one hour of incessant standing and four hours in total per day (Meijsen and Knibbe, 2007).

Prolonged standing in the present study is associated with back and knee pains $(\mathrm{p}<0.05)$ (Table 5), which can be explained by absence of suitable break with sustained standing activities which is considered possible risk for spinal loading.

In the present study, about $35.5 \%$ of respondents were pushing or pulling heavy weights which are a risk factor for back, neck and shoulder pains. This was in consistence with a study done by Munabi et al., 2014 among nurses in Uganda mostly who declare that pushing or pulling heavy weights 
affects the neck and the lower back. The results of another study in Cairo, Egypt reported that pushing or pulling heavy items are associated with ankles, neck, hip and knees symptoms (Abo El Ata et al., 2016). In contrast to another study in South Manchester, UK which found that pushing and pulling were extrinsic worksite predictors of widespread musculoskeletal pain (McBeth et al., 2003). Also, Smedley and his colleagues, 2003 reported that pushing or pulling appeared to affect more shoulders than back.

Our work showed that manual handling of patients was associated significantly with knee and hand pains (Table 5), which is in accordance with other studies which stated that the number of patient manual handling jobs executed per hour associated with the load lifted were significant risk factors of wrist and knee pains ( Menzel et al., 2004 and Smith et al., 2005). Tinubu et al. (2010) concerned that lifting patients is one of the most frequent precipitating factors for musculoskeletal complaints among nurse staff. Alexopoulos et al. (2003) reported that handling of weights will put nurses at risk for musculoskeletal symptoms.
In the current study there was statistically significant association between presence of work shift and presence musculoskeletal symptoms as a whole and also statistically significant association between shift work and back pain, neck, and hand pain (Tables 4,5). Nurses working in a night or rotating shift were more liable to burnout, emotional exhaustion and instability leading to increasing the risk of accidents and injuries, and less work achievement since shift work is a psychosocial risk factor. The results Attarchi and his colleagues suggest that shift work raised the frequency of low back pain among nurse staff (Attarchi et al., 2014). In another study among nurses, $71.7 \%$ of nurses are working in shifts and shift work correlates proportionally with lower back and hips symptoms (Abo El Ata et al. 2016). While a study achieved among Iranian nurses in operation room reported that back, knees and neck pains are associated with shift work (Choobineh et al., 2010). A study conducted by Trinkoff et al. and a systematic review accomplished by Ellapen and Narsigan conclude that adverse working schedules was statistically significant extrinsic risk 
factor for WMSD. Improved schedules with reduced overtime and less work on days off could diminish risk of WMSD and retrieval time (Trinkoff et al., 2006; Ellapen and Narsigan, 2014). These results of our work were in accordance with (Cameron et al., 2008)who stated that predisposing factors for neck, back and shoulders symptoms include prolonged shifts with insufficient sleep and manual handling of patients.

\section{Conclusion}

A high frequency of Egyptian nurses reported WMSDs at some body sites with the low back being most injured site. Nurses in inpatients and ICU departments were more affected than outpatients. Working in the awkward positions for extended periods, presence of working shifts and concentration for long periods were the most perceived job risk factors for MSS. More than two thirds of nurses showed affection of daily life and need for treatment. Coping strategies and health education on prevention of musculoskeletal disorders are recommended.

\section{Conflict of interest}

There were no conflicts of interests.

\section{Acknowledgment}

The author would like to acknowledge CCOHS Canadian center for occupational health and safety for providing symptoms survey for WMSDs checklist that give an important guidance in designing the questionnaire which used to complete data collection for this study.

\section{References}

1. Abo El Ata G, El Desouky S, Manawil M and Khalifa E (2016): Assessment of work- related musculoskeletal symptoms in operation room nurses. Curr Sci Int; 5 (2):215-22.

2. Alexopoulos EC, Burdorf A and Kalokerinou A (2003): Risk factors for musculoskeletal disorders among nursing personnel in Greek hospitals. Int Arch Occup Environ Health; 76 (4):289-94.

3. Anap DB, Iyer C and Rao K (2013): Work related musculoskeletal disorders among hospital nurses in rural Maharashtra, India. International Journal of Research in Medical Sciences; 1(2):101-7.

4. Attarchi M, Raeisi S, Namvar M and Golabadi M (2014): Association between shift working and musculoskeletal symptoms among nursing personnel, Iran. J Nurs Midwifery Res; 19:330914.

5. Bernal D, Campos-Serna J, Tobias A, VargasPrada $S$, et al (2015): Work-related psychosocial risk factors and musculoskeletal disorders in hospital nurses and nursing aides: a systematic review and meta-analysis. Int $\mathrm{J}$ Nurs Stud; 52(2):635-48.

6. Bongers PM, Kremer AM and ter Laak J (2002): Are psychosocial factors, risk factors elbow, or hand/wrist? A review of the epidemiological literature. Am J Ind Med; 41:315-42. 
7. Botha WE and Bridger RS (1998): Anthropometric variability, equipment usability and musculoskeletal pain in a group of nurses in the Western Cape. Appl Ergon; 29:481-90.

8. Cameron SJ, Armstrong-Stassen M, Kane D and Moro FB (2008): Musculoskeletal problems experienced by older nurses in hospital settings. Nurs Forum; 43:103-14.

9. Canadian Center for Occupational Health and Safety (2013): Medical history checklist: symptoms survey for work-related musculoskeletal disorders (WMSDs) [Online], [cited 2016 November 22]; Available from: URL: https://www.ccohs.ca/oshanswers/ diseases/work_related_WMSD.html

10. Choobineh A, Movahed M, Tabatabaie SH and Kumashiro M (2010): Perceived demands and musculoskeletal disorders in operating room nurses of Shiraz city hospitals. Industrial Health; 48:74-84.

11. Daraiseh N, Cronin SN, Davis LS, Shell RL, Karwowski W et al (2010): Low back symptoms among hospital nurses, associations to individual factors and pain in multiple body regions. International Journal of Industrial Ergonomics; 40(1):19-24.

12. Ellapen TJ and Narsigan S (2014): Work Related Musculoskeletal Disorders among Nurses: Systematic Review. J Ergonomics; S4:S4:003-008.

13. Hagberg M, Violante FS, Bonfiglioli R, Descatha A, Gold J, et al (2012): Prevention of musculoskeletal disorders in workers: classification and health surveillance statements of the Scientific Committee on Musculoskeletal Disorders of the International Commission on Occupational Health, BMC. Musculoskelet Disord; 13:109-116.

14. Hegazy AA, Awadalla NJ and Shenouda NS (2009): Prevalence of musculoskeletal complaints among dentists in some Egyptian cities. Egyptian Journal of Occupational Medicine; 33(1): 55-71.

15. Josephson $M$, Lagerström $M$, Hagberg $M$ and Hjelm EW (1997): Musculoskeletal symptoms and job strain among nursing personnel: a study over a three year period. Occup Environ Med; 54:681-5.

16. Kee D and Seob S (2007): Musculoskeletal disorders among nursing personnel in Korea. International Journal of Industrial Ergonomics; 37(3):207-12.

17. Kuorinka I, Jonsson B, Kilbom A, Vinterberg H, Biering-Sorensen F, et al (1987): Standardized Nordic Questionnaires for the analysis of musculoskeletal symptoms. Appl Ergon; 18:233-7.

18. McBeth J, Harkness EF, Silman AJ and Macfarlane GJ (2003): The role of workplace low-level mechanical trauma, posture and environment in the onset of chronic widespread pain. Rheumatology; 42:1486-94.

19. Meijsen P and Knibbe HJ (2007): Prolonged standing in the OR: a Dutch research study. AORN J; 86(3):399-414.

20. Menzel NN, Brooks SM, Bernard TE and Nelson A (2004): The physical workload of nursing personnel: association with musculoskeletal discomfort. International Journal of Nursing Studies; 41(8):859-67.

21. Munabi IG, Buwembo W, Kitara DL, Ochieng J and Mwaka ES (2014): Musculoskeletal disorder risk factors among nursing professionals in low resource settings: a cross-sectional study in Uganda. BMC Nursing; 13:7-15.

22. Nelson A, Fragala G and Menzel N (2003): Myths and facts about back injuries in nursing. American Journal of Nursing; 103(2):32-40.

23. Nur Azma BA, Rusli BN, RM Noah, Oxley JA and Quek KF (2016): Work Related Musculoskeletal Disorders in Female Nursing Personnel: Prevalence and Impact. International Journal of Collaborative Research on Internal Medicine and Public Health; 8(3):294-98.

24. Smedley J, Inskip H, Trevelyan F, Buckle P, Cooper C, et al (2003): Risk factors for incident neck and shoulder pain in hospital nurses. Occup Environ Med; 60(11):864-9.

25. Smith DR and Leggat PA (2003a): Musculoskeletal disorders in nursing. Aust Nurs J; 11:1-3. 
26. Smith DR, Leggat PA, Smyth W and Wang RS (2003b): Musculoskeletal disorders among female Australian nurses working in a unique tropical environment. Ergon Aust; 17:14-7.

27. Smith DR, Choe MA, Jeon MI and Chae YR (2005): Epidemiology of Musculoskeletal Symptoms among Korean Hospital Nurses. International Journal of Occupational Safety and Ergonomics; 11(4):431-40.

28. Smith DR, Mihashi M, Adachi Y, Koga H and Ishitake T (2006): A detailed analysis of musculoskeletal disorder risk factors among Japanese nurses. J Safety Res; 37(2):195-200.

29. Smith DR, Wei N, Kang L and Wang RS (2004): Musculoskeletal disorders among professional nurses in mainland China. J Prof Nurs; 20:3905.

30. Sorour AM and Abd El-Maksoud MM (2012): Relationship between musculoskeletal disorders, job demands, and burnout among emergency nurses. Adv Emerg Nurs J; 34(3):272-82.

31. Taghinejad H, Azadi A, Suhrabi Z and Sayedinia M (2016): Musculoskeletal disorders and their related risk factors among Iranian nurses. Biotechnology and Health Sciences; 3(1):e34473.

32. Tinubu BM, Mbada CE, Oyeyemi AL and Fabunmi AA (2010): Work-related musculoskeletal disorders among nurses in Ibadan, South-west Nigeria: a cross-sectional survey. BMC Musculoskelet Disord; 11:12-19.

33. Trinkoff AM, Lipscomb JA, Geiger-Brown J and Brady B (2002): Musculoskeletal problems of the neck, shoulder and back and functional consequences in nurses. Am J Ind Med; 41:1708.

34. Trinkoff AM, Geiger-Brown J, Brady B, Lipscomb J and Muntaner C (2006): How long and how much are nurses now working? Am J Nurs; 106:60-71.

35. Wilkinson WE, Salazar MK, Uhl JE, Koepsell TD, DeRoos RL, et al. (1992): Occupational injuries: a study of health care workers at a northwestern health science center and teaching hospital. Am Assoc Occup Health Nurs J; 40:287-93.

36. Yasobant S and Rajkumar P (2014): Workrelated musculoskeletal disorders among health care professionals: A cross-sectional assessment of risk factors in a tertiary hospital, India. Indian Journal of Occupational and Environmental Medicine; 18 (2):75-82.

37. Yip YB (2001): A study of work stress, patient handling activities and the risk of low back pain among nurses in Hong Kong. J Adv Nurs; 36:794-804. 